\title{
The political marketing planning process: improving image and message in strategic target areas
}

\author{
Paul R. Baines \\ Middlesex University Business School, London, UK \\ Phil Harris \\ Manchester Metropolitan University, Manchester, UK \\ Barbara R. Lewis \\ Manchester School of Management, Manchester, UK
}

\section{Keywords \\ Marketing, Planning, Politics}

\section{Abstract}

A marketing planning framework to aid political parties in improving their image and co-ordinating election campaigns has been developed to reflect the changing nature of electoral campaigning in the developed world towards the need for more long-term planning together with the development and implementation of marketing models in a wider sphere of social situations. The planning model has been developed using both a hypothetico-deductive and an inductive approach, incorporating recent developments in US and UK political campaign management and depth interviews with political strategists in the UK. Suggests that national political parties need to co-ordinate their election campaigns more effectively in order to strengthen their image among key citizen and voter groups by determining which target areas are most in need of resources. Further research is needed to determine how to position the party and to select and place advertising in the relevant media. Concludes that local election campaigns are becoming more co-ordinated by national parties but that such coordination neglects to provide local area research and telemarketing campaigns, and post-election analysis exercises to monitor strengths and

weaknesses in party strategy and campaign plan implementation.

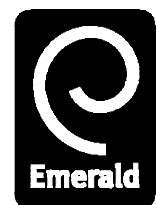

Marketing Intelligence \&

Planning

20/1 [2002] 6-14

(C) MCB UP Limited

[ISSN 0263-4503]

[DOI 10.1108/02634500210414710]

\section{Introduction}

The major political parties in the developed world are beginning to embrace the marketing concept and process. The UK Conservative Party has used the services of Saatchi and Saatchi in the 1980s, as did the Irish President, Mary Robinson in her campaign in the 1990s (Dunnion, 1998). The British Labour Party has incorporated focus groups in its 1990's activities (see Gould, 1998). In Germany, the Green Party and SPD used marketing management techniques to defeat Helmut Kohl (Baines et al., 1999a).

Nevertheless, marketing planning for political parties has, until now, been neglected in the literature and there appears to be a lack of consideration of the strategic components associated with political marketing campaigns (Butler and Collins, 1996; Farrell, 1996; O’Cass, 1997; Baines et al., 1999b).

In this article, findings from a recent research investigation, which focused on developing a marketing planning model for political parties in the UK, are outlined. The research incorporates discussion of campaigning techniques with UK Members of Parliament and senior party workers and outlines a marketing planning framework for political parties. Discussion of this model includes: information gathering and constituency identification, competition and voting group determination, party positioning and voter group targeting, and post-election analysis.

\section{The emergence of political marketing}

Political marketing as an academic discipline is a relatively new and embryonic area. Most current definitions of political marketing
(Shama, 1975; Lock and Harris, 1996; Wring, 1997) identify the political marketing process as concerned more with the communication process between voters and political entities (either parties or candidates) neglecting organisational components.

The relevance of particular aspects of marketing theory for political entities has been illustrated by numerous authors, e.g. the relevance of the marketing mix for political parties (O'Leary and Iredale, 1976), and the use of ACORN as a segmentation base for voter targeting (Yorke and Meehan, 1986). However, as Smith and Saunders (1990) have identified, it is through the more strategic use of marketing techniques that the target markets' wants and needs, and the necessary policy decision-making to satisfy these wants more effectively, will truly emerge. In order to bridge the gap between what the voters want from a potential government and what candidates and parties propose (whilst still generating ideologically credible policy and image platforms), the use of marketing planning is advocated.

\section{Marketing planning and political parties: the odd couple?}

Lock and Harris (1996) have suggested that "political marketing as a discipline has to develop its own frameworks, adapting those from the core marketing literature and, second, that it has to develop its own predictive and prescriptive models if it is to inform and influence political action". The model, put forward in this paper, which illustrates co-ordinated campaigning is intended to adhere to this theme and serve the purpose of ensuring that political parties compete for public support[1] more efficiently and effectively. 
$\overline{\text { Paul R. Baines, Phil Harris and }}$ Barbara R. Lewis

The political marketing

planning process: improving

image and message in

strategic target areas

Marketing Intelligence \&

Planning

20/1 [2002] 6-14
The arguments that political campaigns cannot run on a strategic level fail to recognise the significant efforts of the US Republican Party in the 1980s, and the British Labour Party in the 1990s - both of which had had poor party images - to rebuild their reputations and improve their electoral success through the combined use of polling, qualitative research, coherent advertising themes, and effective strategy teams focussing on message development and deployment, and party re-organisation. The timescale of conducting such campaigns stretches beyond the formal election campaign period (four or five weeks in the UK, one year in the USA). The UK Labour Party put together a campaign management team in 1985 for the 1987 election (Smith, 1994).

Not surprisingly, there are aspects of the political campaigning process that are described more effectively using concepts from political science rather than marketing. Particularly pertinent examples of these phenomena include: ticket-splitting (where voters vote for a different party for two or more political offices, i.e. the USA especially); traditional, personal and tactical voting behaviour from a consumer behaviour perspective (phenomenon particularly associated with the UK); canvassing (particularly in less developed countries such as Namibia); and comparative and negative advertising from a communications standpoint (stronger in the USA). From a competitive perspective, political parties operate in situations which are relatively more akin to an oligopoly than the general consumer marketing perspective generally (though not necessarily) associated with more perfect competition. Nevertheless, there are many similarities between political marketing and traditional fast moving consumer goods marketing (FMCG) and it can be argued that the differences have been overstated (see Egan, 1999).

Nevertheless, in the light of these apparent differences between the two subject disciplines (Butler and Collins, 1994; Lock and Harris, 1996), and the fact that there appears to be a high degree of synergy between political campaigning and marketing (Mandelson, 1988; O’Cass, 1996), there is a need to determine the area of overlap between marketing and political campaigning as techniques for informing, communicating with, "connecting" with, persuading and reaching the electorate (and citizens generally) inside and outside an election cycle.

Earlier political marketing models (such as those described by Newman (1994) and
Maarek (1995)) have neglected to emphasise the importance of local campaigning and its organisational implications; a particularly important process in political campaigns operating with constituency-based systems. Both models assume that segmentation and targeting takes place within the national context only. Local campaigning has been neglected in the political marketing literature, despite political scientists' estimations that such efforts can affect the vote significantly, particularly in marginal constituencies (see Curtice and Steed, 1980; Norton and Wood, 1990; for opposing views on the importance of local campaigning).

Local campaigning is becoming increasingly important in first-past-the-post electoral systems (which operate in the UK and the USA) since the priority is not to get an overall majority of individual votes but to obtain an overall majority of individual seats. Local campaigning is also important in other electoral systems such as those using single transferable vote (STV) and alternative vote (AV) systems. Thus, the implication that one area is more important than another gives rise to the need to target those areas that are more likely to change their allegiance (see Niffenegger, 1989; for a discussion of this concept from a US perspective). Any electoral system which relies on constituencies as the primary electoral unit has this in-built facet that some constituencies may be more important than others in determining the election outcome.

McDonald (1989) describes the purpose of marketing planning as "the identification and creation of competitive advantage". Political marketing planning[2] aims to determine how to generate and retain public support for party policies and programmes. The creation of competitive advantage occurs through the determination and conduct of the party's positioning strategy and the consistent communication of this strategy in defined key areas of the country in the local context, as well as nationally through the broadcast channels (press, radio, television).

Table I has been developed using five factors associated with strategic marketing planning (Palmer, 1994) and illustates how marketing planning is being used for political campaigning.

The framework for co-ordinated local campaigning, put forward in this article, attempts to incorporate these five key requirements of marketing planning into a cohesive framework. It is likely that coordinated local campaigning will become an area of growth in what could transpire to 
Paul R. Baines, Phil Harris and

Barbara R. Lewis

The political marketing

planning process: improving

image and message in

strategic target areas

Marketing Intelligence \&

Planning

20/1 [2002] 6-14
Table I

The factors associated with political marketing planning

Marketing planning function Political marketing context

Market position analysis This requires a determination of how voters perceive the parties and individual candidates in different areas of the electoral battleground. It may be that the parties' competitive positions are different in different regions of the country

Objective setting

The party needs to determine which issues it will compete on and which voter and citizen groups it will try to resonate with and whether or not this is possible within the constraints of the organisation

Strategic alternative evaluation

Which segments of the electorate should parties communicate with, using which messages? Should multiple segments be targeted with multiple messages? Public opinion polling and qualitative research can be used to guide and develop message development and receipt, and measure and assess segmented groups' stability, accessibility and substance

Strategy implementation

The political strategist needs to allocate the necessary resources to the targeting process involving message dissemination through press, radio, television (both adverts and publicity) and direct mail. In political campaigns, one major problem occurring is one of uncertainty regarding the flow of donations that will be received by the party. Thus, parties have experienced financial difficulties in the past (e.g. the British Conservative Party's sizeable overdraft after the 1992 British General Election). This largely depends on the system of public financing which is operating in the country concerned

Monitoring and control

Since the marketing planning process attempts to match organisational resources with market opportunities and threats, whilst considering the organisation's strengths and weaknesses, the process of monitoring the external environment and evaluating a particular strategy's impact upon that environment is paramount. In the political context, there is a need to determine whether or not segmented voter groups have been targeted properly with the correct messages. In the UK, the Labour Party conducted large numbers of focus groups after its failure in the 1992 election (Gould, 1998) whilst Bob Dole, the failed presidential candidate in the USA, also had one of his consultants conduct a "post-mortem" (personal interview with US political consultant, W ashington DC, January 1998). Bob Worcester (1999) recommended conducting post-election analysis to British Prime Minister Harold Wilson in 1974 become a Europe of Regions and the recent trend advocated by the UK Labour Party for more direct contact with the public, in the form of referenda (e.g. Welsh and Scottish devolution, a strategic Greater London Authority, Euro entry etc.).

\section{Methodology}

The objective of this research study was to produce a marketing planning model for political parties in the UK political system, but one that could also be used by other political parties operating in constituencybased electoral systems (particularly firstpast-the-post) around the world. This model aims to aid political strategists in determining which local areas, and floating voters within them, are most at risk of switching their allegiance from one party to another.
In-depth interviews were carried out during February to April 1996 with five Members of Parliament and one party agent for six marginal constituencies in the UK: Rochdale, Oldham East and Saddleworth, Hazel Grove, Batley and Spen, Dewsbury and Bradford South. In addition, in-depth interviews were held with three senior campaign executives: the Key Seats Manager of the UK Labour Party; the Director of Campaigns and Communications of the UK Liberal Democrats; and the Director of Campaigning for the UK Conservative Party.

The interviews were designed to determine the method of campaigning that political parties currently used to assess whether or not it could be refined into a marketing planning model. Analysis of the interviews, from a marketing planning perspective, revealed a number of important points. The campaign executive for the Labour Party stated that they would target 90 seats for the 
Paul R. Baines, Phil Harris and Barbara R. Lewis

The political marketing

planning process: improving

image and message in

strategic target areas

Marketing Intelligence \&

Planning

20/1 [2002] 6-14
1997 UK General Election. These seats were all held by the main opposition parties (mostly Conservative but a few were Liberal Democrat) and the vast majority needed swings of less than 5.0 per cent[3]. The director of campaigning for the Conservatives stated that they were interested in about 100 seats and that the allocation of resources (in terms of targeting seats) depended on the importance of the local candidate and patterns of migration in each individual seat. The director of campaigns for the Liberal Democratic Party also stressed the importance of local factors:

Yes, local factors are important to us and they are cultivated by our camps on the ground. When we tend to win it is often because we have a strong, effective, local candidate who is in touch with the local issues and who has built a strong personal following. The personal vote is much more important on the Lib Dem side than it is if you are a Conservative or Labour candidate.

The central premise of the targeting approach in this research is that the constituencies which are currently most at risk of switching their allegiance can be identified by comparison with constituencies that were in a similar state (in terms of majority[4] and the swing required) at a previous election.

\section{A marketing planning framework for political parties}

A marketing planning framework needs to take into account the realities of the environment and allow for rapid change (e.g. partisan allegiance, changes in public opinion). The framework (see Figure 1) should incorporate the detail of the various political phenomena (e.g. tactical voting, traditional voting, personal voting, the importance of by-elections, defections, deselections and immigration/emigration patterns) in order to reflect the reality of the campaigning process.

\section{Planning model stage 1: information} gathering and constituency identification In this stage, constituencies that are most likely to change their allegiance are identified, since such constituencies are particularly important and resources can be targeted more effectively at these constituencies, thus, saving political parties both money and time.

Historical data

Knowing the party's vote-share and major source of competition at the previous election is important when targeting constituencies and in the determination of how the candidate and local party should attempt to persuade the electorate that their message is more appropriate than that of a rival party.

\section{Census statistics}

The political strategist needs to monitor the demographic structure of the constituency on an ongoing basis so that changes can be identified and key voters and citizen groups (outside an election) located so that appropriate action can be taken. Thus, census data statistics are important in determining the location of the relevant groups since socio-economic (and other relevant targeting) data may have been mapped in the census.

\section{Constituency ranking}

In a first-past-the-post electoral system, a simple majority of seats needs to be gained for a party to form government. Often, these seats are closely contested and main opposition parties attempt to gain as many as practically possible from the incumbent party in order to form a majority. Each party should determine the swing needed to gain a seat. Using constituency research and canvass records, tactical, traditional and personal voting adjustments can then be made to the electorate (excluding non-voters) to give a "perceived audience" for each party for each constituency. If the "perceived audience" is subtracted from the required swing (expressed in terms of numbers of voters) for a particular constituency (see equation below) then one is left with the potential majority which can be achieved at the election. The individual constituencies can then be ranked in terms of the sizes of their potential majorities. Constituencies lower in the ranking list should not receive the same level of resources as other constituencies of higher ranking, since they are less likely to change their political allegiance[5].

\section{Ranking equation:}

Perceived audience - Required swing[6] = Potential majority

The combination of constituency research, census statistics, canvass records and historical data allows the political strategist to determine the principal competition and who are the relevant groups that need to be targeted. Shea (1996, p. 68) has stated that "together, demographic research, survey data and prior electoral data merge to form a powerful targeting weapon". Such data should also give an indication of the level of tactical and personal voting. 
Paul R. Baines, Phil Harris and Barbara R. Lewis

The political marketing

planning process: improving

image and message in

strategic target areas

Marketing Intelligence \&

Planning

20/1 [2002] 6-14

$\overline{\text { Figure } 1}$

Political planning model for local campaigning

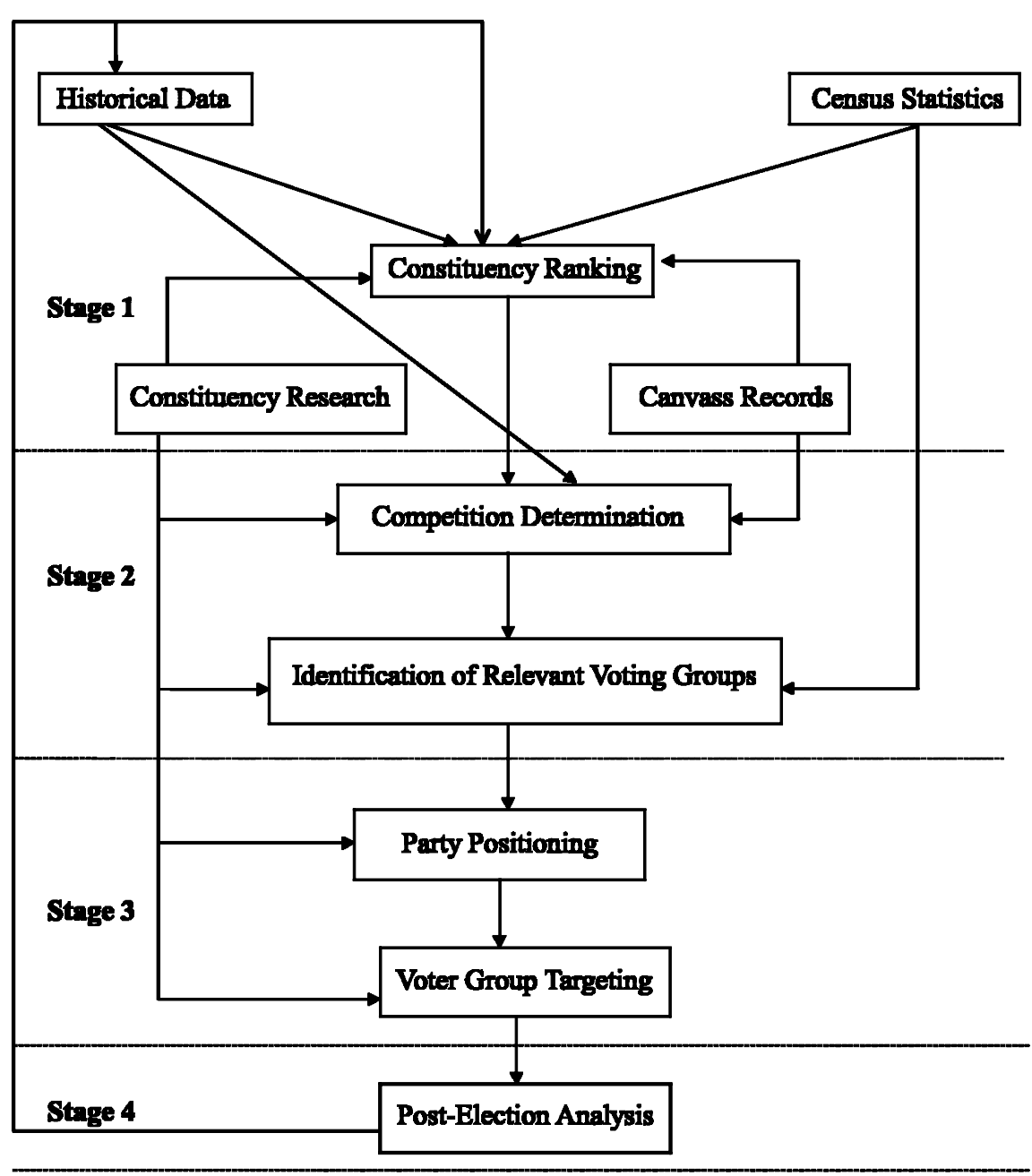

Source: Baines et al. (1999c)

\section{Constituency research}

Constituency research is vital for a full understanding of the current position of the major parties within a constituency, since historical voting data does not give any idea of recent changes in the partisan nature of the seats. Constituency research should focus on:

- current level of support;

- types of people who support particular parties (indicating the major competition);

- types of people who have changed their support for a particular party since the previous General Election;

- electorate's feelings regarding particular issues and policies;

- level of tactical and traditional voting; and

- whether or not the personal vote is significant.

Constituency research feeds into most aspects of the political planning process. The national party should conduct surveys in the target constituencies, i.e. those that are ranked highest in the ranking exercise, in order to provide a current overview of the political situation. This research should determine voters' partisan allegiance in the different constituencies, thus providing an indication of which party is in closest contention whilst also attempting to determine which messages will "connect" most with the floating voters within a particular constituency. It has been rare, in the past, for political parties in most Western European countries to research constituencies systematically in the manner described above, probably due to the lack of market orientation and the lack of its perceived importance. This is slowly changing (see Plasser et al., 1998).

\section{Canvass records}

Canvassing the electorate helps parties in targeting individual voters on election day in the get-out-the-vote (or "knocking up") effort. 
$\overline{\text { Paul R. Baines, Phil Harris and }}$ Barbara R. Lewis

The political marketing

planning process: improving

image and message in

strategic target areas

Marketing Intelligence \&

Planning

20/1 [2002] 6-14
Canvassing should be undertaken in order to determine the supporters of the particular parties, e.g. floating voters, so that the local constituency organisations can tailor specific messages to the relevant sections of the electorate for voter persuasion.

\section{Planning model stage 2: competition and} voting group determination

This stage concerns determining the main competition and segmenting the various voter groups, incorporating all the recent data from canvassing and constituency research.

\section{Competition determination}

The political strategist needs to determine which party provides the biggest threat within each individual seat so that he/she can then provide an appropriate policy platform to counteract the opposing parties. Generally, the determination of the competition within a seat is best provided by a combination of previous general election voting data and other election results[7]. This information should allow the strategist to determine which sub-areas within a particular constituency are more likely to vote for a particular party. This is an important process since certain sub-areas within marginal constituencies may contain more or fewer marginal voters. Thus, the process of competition determination is, to some extent, a by-product of the constituency ranking and research exercises.

\section{Segmentation of relevant voting groups} In order for the parties to change or keep a seat's allegiance, they need to approach those voters who are most likely to change their vote to the main opposition party (except where a third, and even fourth, party is in very close contention with the incumbent). Constituency research should help to point out useful segmentation bases (particularly using CHAID analysis - a technique commonly used by US political campaigners). Those segments which are most important, in either securing a seat or changing a seat's allegiance, would then be targeted using appropriate media.

\section{Planning model stage 3: party positioning and voter group targeting}

In this stage, strategists are concerned with which issues the electorate considers are important and how to disseminate appropriate messages.

\section{Party positioning}

In order to increase their own support, political strategists typically use policies, issues, ideology and reasoned argument, as well as style of presentation, to attempt to win the battle for the minds of the voters. Positioning is the process of "connecting" with voters: the process of developing a campaign theme that consists of convergent policy stances on issues. Bradshaw (1995, p. 43) defines theme as "the rationale for your candidate's election and your opponents' defeat. It is the single, central, idea that the campaign communicates to voters to sum up the candidate's connection with the voters and their concerns and the contrast between your candidate and the opponent".

Party positioning is a crucial aspect of the political marketing process because the strategist uses it to set out the policies which the party applies to persuade the electorate (and citizens) to support them inside and outside an election. It is also important to note that parties need to select a theme (e.g. policy on Europe) and aspects of that theme (e.g. specific policies relating to further integration, agriculture etc.) which connect with voters. Selection of this theme becomes paramount because parties cannot later attempt to use a theme which is not consistent with their original policies, statements and ideology since this may well be picked up by the opposition parties' media spokespeople in a process known as rapid rebuttal which may, subsequently, be picked up by the media or directed at the media by opposition party spin-doctors. Specific policies should be directed at voters in terms of how concerned with the particular policy the electorate is and the extent to which the policy fits the political entity's ethos (Baines et al., 1999b).

Although research is being conducted in the USA and Western Europe into how to position candidates and parties by either the parties themselves or campaign committees, the process is relatively less sophisticated in Western Europe (Plasser et al., 1998), principally due to the lack of market orientation that most parties have in major Western European countries. This trend is changing due to the use, by European political parties, of US political consultants as advisors in recent elections (Plasser et al., 1998).

\section{Voter group targeting}

Once the agenda for the constituency has been developed and the political strategist has determined the targets, the constituency organisation will generally deliver its message through door-to-door canvassing, telephone canvassing, direct mail and local meetings. Different constituencies usually adopt a mix of different methods, for example in a rural constituency, a certain amount of telephone canvassing might occur in order to save time and expense. 
$\overline{\text { Paul R. Baines, Phil Harris and }}$ Barbara R. Lewis

The political marketing

planning process: improving

image and message in

strategic target areas

Marketing Intelligence \&

Planning

20/1 [2002] 6-14

\section{Planning model stage 4: post-election} analysis

The essence of good marketing planning is to learn from previous successes and failures and to build these into future planning strategy.

The party should ensure that a positive image is maintained outside the election cycle. This stage attempts to determine what lessons can be learned from previous strategies.

\section{Post-election analysis}

Post-election analysis aims to determine whether or not the correct voter segments were targeted successfully. This requires further research into why the electorate voted the way that it did. In addition, the constituency results may be used to increase the accuracy of the constituency ranking exercise, since one will be able to compare the actual majorities with the potential majorities at the end of the election.

The constituency results will also allow the party consultants and managers to further refine the segmentation bases used, since post-election analysis and research will indicate whether the correct segments were targeted and whether they received (and believed) the messages directed at them.

\section{The boundaries of the political marketing planning model}

Tactical, personal and traditional voting are all considerations which are taken into account in the model when deciding which constituencies to allocate the available resources to and which voters to target within these constituencies. However, such factors are in continual flux and their estimation is a difficult and time-consuming process. Many politicians genuinely feel that marketing has no place in politics and so they resist attempts to orient themselves and their parties more towards the populace they exist to serve.

The effect of the political corporate culture on marketing planning is not considered in this paper (see McDonald, 1989; Saker and Speed, 1992; Leppard and McDonald, 1991 for a general consideration of its effects on commercial marketing organisations) although O'Cass (1997) suggests that political parties in Australia have found the market orientation process difficult. The effects of the political system on marketing activity (Baines et al., 1999a) are not considered within the scope of this paper.

\section{Implications for political parties and candidates}

Political parties are becoming more organised in their campaigning activity and more market-oriented. Despite this, many European political parties still do not provide their local campaign teams with positioning, voter group and post-election data, nor do they encourage local campaign teams to get this information themselves. The recent case in Newark, in the UK, where the victorious Labour MP had to stand down due to election expenses fraud (and was subsequently reappointed on appeal), principally arising due to the cost of launching a telemarketing campaign, illustrates the need for the national party to monitor and co-ordinate all constituency activity carefully.

Many of the stages of the planning model were gleaned from interviews with the different UK Members of Parliament although they did not all exhibit the different stages in their campaigns. Since marginal seats are so important to the national parties, and in order to work within election law relating to expenses (which differ from country to country), political parties need to commission marketing research and telemarketing campaigns that transcend constituency boundaries. This increase in activity needs to be financed through more intensive lobbying and direct mail fundraising campaigns. Once the campaigns have been conducted, it is important to determine why the campaigns fared in the way that they did (something that most constituency parties neglect to do).

\section{Conclusion}

Targeting key voter groups within the election cycle is important if parties are to retain, or gain, office. Similarly, parties also need to maintain and enhance their image and policies outside the election cycle, if they are to succeed in the current political climate. The framework put forward in this article attempts to illustrate how parties across the world can more effectively co-ordinate their campaign activity so that local campaigns are speaking with the same voice as the national campaign. Local campaign teams, particularly in countries with lesser developed political campaigning culture, can effectively be likened to franchises (Egan, 1999). The result is that local campaigns are often perceived as insufficiently important and are underutilised, despite their significance on voteshare (particularly where the candidate is very popular, e.g. the former Liberal and Liberal Democrat candidate, Cyril Smith, in Rochdale in the UK) and party image.

The authors have attempted to demonstrate, in this article, that in order to 
Paul R. Baines, Phil Harris and Barbara R. Lewis The political marketing planning process: improving image and message in strategic target areas

Marketing Intelligence \&

Planning

20/1 [2002] 6-14 reach and communicate with those voters who are most likely to change their allegiance inside and outside the election cycle, political strategists need to use a structured and planned approach. This includes amassing and analysing constituency data (from various sources), determining who are the main sources of competition, identifying and targeting individuals and groups of voters, and then performing a post-mortem to determine where the process could be modified to make it more efficient in future political campaigns.

\section{Notes}

1 Note that we specifically use "support" rather than "votes" since there are times when parties need to promote themselves outside electoral contests, such as in referenda. This becomes more important in countries where referenda are frequent such as in California, in the USA. Parties also need to win support outside election cycles in order to be effective and receive favourable coverage from the press.

2 Used here in the context of an election campaign as opposed to commercial lobbying or the marketing of government programmes.

3 Swing is the movement of vote-share from the first-placed party in an election to the secondplaced party in a consecutive election.

4 Majority is defined as the difference in share of the vote between the second- and firstplaced parties between two successive elections.

5 The concept of ranking political jurisdictions on the basis of the number of "persuadable voters" has been suggested by a number of authors (see Bradshaw, 1995; Shea, 1996, p. 87).

6 Expressed as a number of voters rather than as a percentage.

7 Except in marginal constituencies, constituencies where there have been exceptional circumstances (e.g. scandal, deselection etc.) and constituencies whose boundaries have been changed.

\section{References}

Baines, P.R., Harris, P. and Newman, B.I. (1999a) "New Realpolitik: political campaigning and the application of political marketing across cultures", Proceedings of the European Marketing Academy Conference, May 1999, Humboldt University, Berlin.

Baines, P.R., Lewis, B.R and Ingham, B. (1999b), "Exploring the positioning process in political campaigning”, Journal of Communication Management, Vol. 3 No. 3

Baines, P.R., Lewis, B.R. and Yorke, D.A. (1999c), "Marketing planning for UK political parties: co-ordinated local campaigning", Proceedings of the Academy of Marketing Conference, July 1999, University of Stirling, Stirling.
Bradshaw, J. (1995), "Who will vote for you and why: designing strategy and theme", in Thurber, J.A. and Nelson, C. (Eds), Campaigns and Elections: American Style. Westview Press, Boulder, CO.

Butler, P. and Collins, N. (1994), "Political marketing: structure and process", European Journal of Marketing, Vol. 28 No. 1, pp. 19-34.

Butler, P. and Collins, N. (1996), "Strategic analysis in political markets", European Journal of Marketing, Vol. 30 No. 10/11, pp. 32-44.

Curtice, J. and Steed, M. (1980), "An analysis of voting”, in Butler, D. and Kavanagh, D. (Eds), The British General Election of 1979, Macmillan Press, London, p. 409.

Dunnion, B. (1998), "Building successful political brands: lessons from the Mary Robinson Campaign", paper presented at the Political Marketing Conference, September 1998, University College, Cork.

Egan, J. (1999), "Political marketing: lessons from the mainstream", Proceedings of the Academy of Marketing Conference, University of Stirling, Stirling, June.

Farrell, D.M. (1996), "Campaign strategies and tactics", in LeDuc, L., Niemi, R.E. and Norris, P. (Eds), Comparing Democracies: Elections and Voting in Global Perspective, Sage Publications, London.

Gould, P. (1998), The Unfinished Revolution: How the Modernisers Saved the Labour Party, Little and Brown, London.

Leppard, J.W. and McDonald, M.H.B. (1991), "Marketing planning and corporate culture: a conceptual framework which examines management attitudes in the context of marketing planning", Journal of Marketing Management, Vol. 7, pp. 213-35.

Lock, A. and Harris, P. (1996), "Political marketing - vive la difference!", European Journal of Marketing, Vol. 30 No. 10/11, pp. 21-31.

Maarek, P.J. (1995), Political Marketing and Communication, John Libbey and Company, London.

Mandelson, P. (1988), "Marketing Labour: personal reflections and experience", Contemporary Record, Vol. 1 No. 4, pp. 11-13.

McDonald, M.H.B. (1989), "Ten barriers to marketing planning", Journal of Marketing Management, Vol. 5 No. 1, pp. 1-18.

Newman, B.I. (1994), The Marketing of the President: Political Marketing as Campaign Strategy, Sage Publications, London.

Niffenegger, P.B. (1989), "Strategies for success from the political marketers", Journal of Consumer Marketing, Vol. 6 No. 1, pp. 45-51.

Norton, P. and Wood, D. (1990), "Constituency service by MPs: does it contribute to a personal vote?", Parliamentary Affairs, Vol. 43 No. 2, pp. 196-209.

O'Cass, A. (1996), "Political marketing and the marketing concept", European Journal of Marketing, Vol. 30 No. 10/11, pp. 45-61. 
$\overline{\text { Paul R. Baines, Phil Harris and }}$ Barbara R. Lewis

The political marketing

planning process: improving

image and message in

strategic target areas

Marketing Intelligence \&

Planning

20/1 [2002] 6-14
O’Cass, A. (1997), "Political marketing in times of discontinuous change", Proceedings of the Academy of Marketing Conference, Manchester Metropolitan University, Manchester.

O'Leary, R. and Iredale, I. (1976), “The marketing concept: quo vadis?", European Journal of Marketing, Vol. 10 No. 3, pp. 146-57.

Palmer, A. (1994), Principles of Services Marketing, McGraw-Hill, London, pp. 46-77.

Plasser, F., Scheucher, C. and Senft, C. (1998), "Is there a European style of political marketing: a survey of political managers and consultants", paper presented to the Political Marketing conference, September 1999, University College, Cork.

Saker, J. and Speed, R. (1992), "Corporate culture: is it really a barrier to marketing planning", Journal of Marketing Management, Vol. 8, pp. 177-81.

Shama, A. (1975), "The marketing of political candidates", Journal of the Academy of Marketing Science, Vol. 4 No. 4, pp. 767-77.
Shea, D.M. (1996), Campaign Craft: The Strategies, Tactics and Art of Political Campaign Management, Praeger Publishers, Westport, CT.

Smith, G. and Saunders, J. (1990), “The application of marketing to British politics", Journal of Marketing Management, Vol. 5 No. 3, Spring, pp. 295-306.

Smith, M.J. (1994), "Neil Kinnock and the modernisation of the Labour Party", Contemporary Record, Vol. 8 No. 3, pp. 555-66.

Worcester, B. (1999), interview with Harold Wilson, 1974, 10 May.

Wring, D. (1997), "Reconciling marketing with political science: theories of political marketing", Proceedings from the Academy of Marketing Conference, Manchester Metropolitan University, Manchester.

Yorke, D.A. and Meehan, S.A. (1986), "ACORN in the political marketplace", European Journal of Marketing, Vol. 20 No. 8, pp. 63-76. 